\title{
Chemical recycling of carbon fibers-reinforced phenolic resin composites by phenol in subcritical conditions
}

\author{
M. Oumam ${ }^{1, *}$, A. K Abourriche ${ }^{2}$, A. M Abourriche ${ }^{3}$, M. Birot ${ }^{4}$, \\ R. Pailler ${ }^{5}$, R. Naslain ${ }^{5}$, H. Hannache ${ }^{1}$ \\ ${ }^{1}$ Laboratoire d'Ingénierie des Matériaux, Faculté des Sciences Ben M'sik, B.P. 7955, Université Hassan II de \\ Casablanca, Morocco. \\ ${ }^{2}$ Laboratoire Matériaux, Procédés, Environnement et Qualité, École Nationale des Sciences Appliquées, \\ B.P.63, 46000 Safi, Morocco. \\ ${ }^{3}$ Laboratoire Biomolécules et Synthèse Organique, Faculté des Sciences Ben M'sik, B.P. 7955, Université \\ Hassan II de Casablanca, Morocco. \\ ${ }^{4}$ Institut des Sciences Moléculaires, Université de Bordeaux, CNRS UMR 5255, F-33405 Talence, France. \\ ${ }^{5}$ Laboratoire des Composites Thermostructuraux, Université de Bordeaux, CNRS/CEA/SAFRAN UMR 5801, F- \\ 33600 Pessac, France.
}

Abstract: In this work, a composite prepared with a phenolic matrix and reinforced with carbon fibers was subjected to degradation by phenol under subcritical conditions. Phenol was able to solubilize the resin matrix under relatively mild conditions $\left(T \leq 390{ }^{\circ} \mathrm{C}, P<0.5 \mathrm{MPa}\right)$ without altering the carbon fibers, as confirmed by scanning electron microscopy and by mechanical characterization of the fibers recovered after heat treatment.

Keywords: Carbon fiber, Phenolic resin, Recycling, Subcritical phenol.

\section{Introduction}

The composites industry is growing in manufacture of 5.7\% per year since 1994. In 2000, 7 million tons were produced, more than $95 \%$ of which were composites of general circulation; and this production reached 10 million tons in 2006 [1]. Today, this growth potential is likely to be hampered by environmental regulation. Currently, over $90 \%$ of waste output in composite materials is dumped in landfill sites (a method with increasing costs and a threat to be banned for waste considered as non-final). The increase in waste production and an increasing global demand for composite materials are the true challenges that will determine the major trends of the composites industry in the coming years.

Industrial waste valorization and recycling are a primordial necessity for environment protection. Such is the case for most polymer-matrix composites (extensively used as structural substituting-steel materials). These composite wastes are usually non-biodegradable. Their difficult valorization and recycling have been the subject of many studies [2-6] that have shown that the development of efficient, low-cost recycling procedures still requires a sustained research effort in order to bring pertinent answers to a variety of questions: (i) what would be the impact of a given composite treatment with a suitable chemical reagent on the properties of the extracted fibers $[7,8]$ or, (ii) how to avoid fiber agglomeration by char when the extraction process is based on combustion in a furnace [9]?

Consequently, the development of simple and innovative treatment processes would be highly useful. For instance, a proper dissolving of the polymer matrices of commonly used composite materials would allow the recycling of undamaged fibers.

Recently, several recycling technologies for carbon fibers-reinforced composites have been studied. Nahil et al. [10] investigated the recycling of carbon fiber-reinforced polymeric waste by pyrolysis at different temperatures in a static bed reactor in order to recover high-value products including gas, condensable products and carbon fibers. Earlier, Bai et al. [11] proposed a procedure based on oxygen in supercritical water $\left(440{ }^{\circ} \mathrm{C}\right.$, $30 \mathrm{MPa}$ ) for recycling carbon/epoxy composites. The recovered carbon fibers kept original strength when the decomposition rates were between 94 and 97 wt.\%. More recently, Liu et al. [12] examined the chemical recycling of carbon fiber-reinforced epoxy resin cured with 4,4' diamino-diphenylmethane in subcritical water. They established a synergistic effect between potassium hydroxide and phenol on the decomposition of this kind of epoxy resin.

The present work aimed to investigate the chemical recycling of carbon fibers from carbon fiberreinforced composites by phenol only in subcritical conditions. 


\section{II.1. Materials}

\section{Experimental}

Carbon/phenolic composites were prepared at LCTS with T300 carbon fibers (Torayca, specifications: $\mathrm{d}=7 \mu \mathrm{m} ; \mathrm{E}=230 \mathrm{GPa} ; \square=3530 \mathrm{MPa}$ ) and Ablaphene RA 101-type resin (Rhodia). The mass fraction of fibers in these samples was about $70 \%$. The composites were manufactured from prepregs (T300 woven / phenolic resin). These prepregs were aligned in a mould and then hot-pressed at $160^{\circ} \mathrm{C}$ under a pressure of 5 $\mathrm{MPa}$

\section{II.2. Degradation of the composite materials by phenol}

Typically (cf. Table 1, run \#2), a sample of composite ( $10 \mathrm{~g})$ was introduced along with phenol $(10 \mathrm{~g})$ into a $120 \mathrm{~mL}$ stainless steel autoclave equipped with a pressure gauge and a tubular furnace (Fig.1). The autoclave was heated to $390{ }^{\circ} \mathrm{C}$ at a heating rate of $16^{\circ} \mathrm{C} \cdot \mathrm{min}^{-1}$. The maximum pressure reached during this treatment was $<0.5 \mathrm{MPa}$. The cooling process was uncontrolled and directed by the oven inertia. After treatment, the recovered fibers were washed with chloroform, dried at $60{ }^{\circ} \mathrm{C}$ and stocked in a sealed plastic bag $(6.67 \mathrm{~g})$.

Table 1: Degradation conditions of the composite materials

\begin{tabular}{lllllll}
\hline Run & $\begin{array}{l}\text { Composite } \\
(\mathbf{g})\end{array}$ & $\begin{array}{l}\text { Phenol } \\
(\mathbf{g})\end{array}$ & $\begin{array}{l}\text { Temperature } \\
\left({ }^{\circ} \mathbf{C}\right)\end{array}$ & $\begin{array}{l}\text { Time } \\
(\mathbf{h})\end{array}$ & $\begin{array}{l}\text { Pressure } \\
(\mathbf{M P a})\end{array}$ & $\begin{array}{l}\text { Solubilization } \\
\text { of the phenolic resin }\end{array}$ \\
\hline $\mathbf{1}$ & 10 & 10 & 390 & 2 & $<0.5$ & Partial \\
$\mathbf{2}$ & 10 & 10 & 390 & 4 & $<0.5$ & Total \\
$\mathbf{3}$ & 10 & 10 & 350 & 6 & $<0.5$ & Partial \\
$\mathbf{4}$ & 10 & 0 & 390 & 4 & --- & No \\
\hline
\end{tabular}

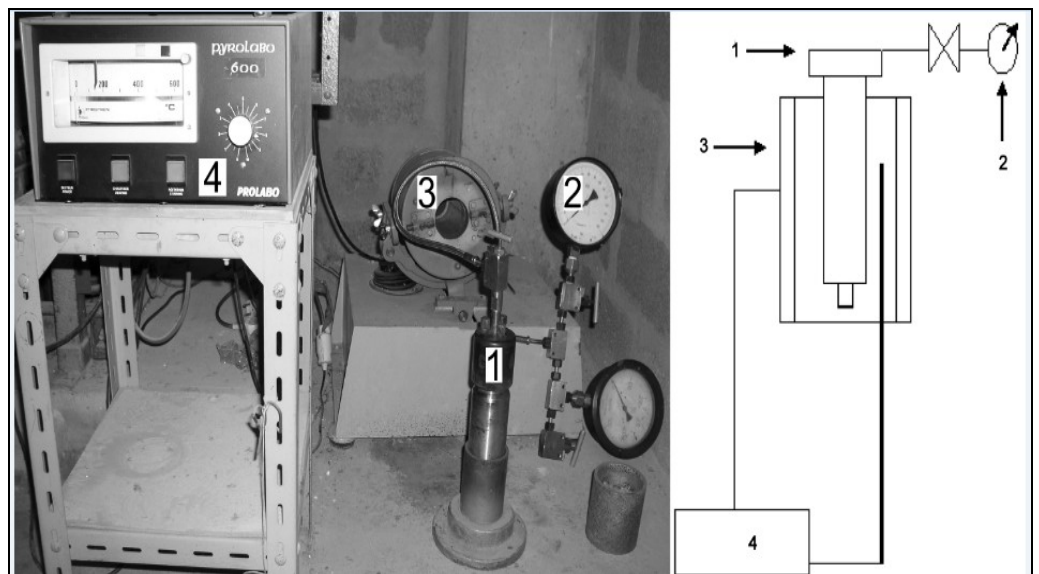

Figure 1: Photograph and diagram of the apparatus used for subcritical extraction: (1) reactor, (2) pressure gauge, (3) furnace and (4) regulator

\section{II.3. Removal of phenol from the recovered liquid residue}

Removal of residual phenol in the recovered liquid residue was carried out in a separating funnel according to the following procedure:

$4 \mathrm{~g}$ of the liquid residue obtained after treatment in the autoclave was solubilized in cyclohexane and placed in a separating funnel. Then, an aqueous solution of $\mathrm{Na}_{2} \mathrm{CO}_{3}$ was added to convert phenol into watersoluble phenolate. After stirring, the two phases separated by decantation. The organic phase was recovered and the aqueous phase was extracted a second time with cyclohexane. The two organic fractions were collected, washed three times with distilled water and dried over anhydrous $\mathrm{Na}_{2} \mathrm{SO}_{4}$. After filtration on Büchner, cyclohexane was evaporated and the obtained, liquid residue free from phenol was dried at $40{ }^{\circ} \mathrm{C}(0.73 \mathrm{~g})$.

\section{II.4. Analyses}

The morphological properties of non-treated and recovered fiber samples were studied by highresolution scanning electron microscopy (SEM) with a JEOL JSM 840A LGS microscope.

Infrared (IR) spectra were recorded between 400 and $4000 \mathrm{~cm}^{-1}$ with a Nicolet 205 FT-IR spectrometer by summing 32 scans at $2 \mathrm{~cm}^{-1}$ resolution. Pellets were prepared by dispersing $2 \mathrm{mg}$ of sample into $198 \mathrm{mg}$ of $\mathrm{KBr}$.

${ }^{1} \mathrm{H}$ and ${ }^{13} \mathrm{C}$ nuclear magnetic resonance (NMR) spectra were recorded at 250 and $63 \mathrm{MHz}$ respectively on a Bruker AC 250 spectrometer. The samples were placed in $5 \mathrm{~mm}$-ID tubes with $\mathrm{CDCl}_{3}$ as solvent. The chemical shifts are given in ppm relative to $\delta \mathrm{TMS}=0 \mathrm{ppm}$. 
Measurement of the fibers diameter was performed by laser interferometry according to ISO 11567:1995 standard. This technique is of prime interest because of its simple implementation and fast measurement. It allows assessing, not only the diameter variation, but also the filament cylindricity by its simple rotation along the fiber axis. The wavelength of a He-Ne laser $(\lambda=0.6328 \mu \mathrm{m})$ was used to determine the average fiber diameter. This measurement is based on the Fraunhofer diffraction principle. The fiber edges act as diffraction slits. The diameter $\mathrm{f}$ was calculated as follows:

$$
f=\frac{2 \lambda d}{i}
$$

where $\lambda$ is the wavelength of the laser beam, $d$ the distance from the fiber to the screen, and $i$ the distance between two consecutive interference rings. A correction of the measurement was made by the relation [13]:

$$
f_{v}=\frac{(f-0.22)}{1.0365}
$$

The resolution increased as the fiber diameter decreased, the accuracy of the measure being about 0.05 $\mu \mathrm{m}$ for a fiber diameter of about $5 \mu \mathrm{m}$.

Mechanical measurements (Young modulus and tensile strength) were performed on 20 fibers of each sample using a laboratory-made tensile testing machine, according to European standards BS EN 1007-4:2004 (speed of constant deformation: $\mathrm{v}=1 \%$ of the length of the gauge by minute). The supported load by fibers was measured using a force sensor connected to the fixed bit. The mobile bit displacement was assessed with a micrometric table controlled by a tracer table and with computerized data acquisition. The fibers were taken up on a paper frame and the used gauge length was $25 \mathrm{~mm}$.

The load cell was a homemade sensor with a maximal load of $150 \mathrm{~g}$. The accuracy was less than $0.1 \mathrm{~g}$ on the total range. The measured displacement was corrected taking into account the deformation of the load cell and the small displacement of the fiber inside the glue for each given load applied to the fiber.

\section{Results And Discussion}

In preliminary experiments, partial solubilization of the organic matrix was noticed when sample of composite was treated by phenol in the autoclave. These results encouraged further investigation into optimizing the degradation conditions. Therefore, the temperature and the treatment time were varied. Table 1 presents the data of the composite degradation. A temperature of $390{ }^{\circ} \mathrm{C}$ and a length of $4 \mathrm{~h}$ were determined as the optimal conditions for extracting almost completely the phenolic resin from the composite (Table 1, entry \#2). Under these conditions, $6.67 \mathrm{~g}$ of carbon fibers, representing 95\% of the initial amount, and $11.24 \mathrm{~g}$ of liquid residue soluble in chloroform were recovered. At lower temperature or shorter reaction time, only partial solubilization was observed (Table 1, entries \#1 \& 3). At $390{ }^{\circ} \mathrm{C}$ in the absence of phenol (Table 1, entry \#4), there was no solubilization of the phenolic resin. During all these attempts, the maximal pressure measured was always $<0.5$ $\mathrm{MPa}$, under the critical point of phenol $\left(\mathrm{T}=419{ }^{\circ} \mathrm{C}, \mathrm{P}=6.1 \mathrm{MPa}\right)[14,15]$. The Fig.2 presents the starting composite sample (Fig.2a) and the recovered fibers after treatment by phenol at $390{ }^{\circ} \mathrm{C} \mathrm{(Fig.2b).}$

The solubilization of the resin can be explained by the reactivity of phenol. Phenols are thermally stable molecules associated by intermolecular hydrogen bonds. Moreover, the $\mathrm{O}-\mathrm{H}$ group is able to react with most organic functions, which would cause the decomposition of large molecules, and consequently would lead to soluble fragments of smaller size. This assumption agrees with the transalkylation reactions between 350 and $550{ }^{\circ} \mathrm{C}$ reported by Leach [16]. Moreover, the reactivity of phenol, with respect to other organic functions, was already noticed in the degradation of oil shale kerogens $[17,18]$.
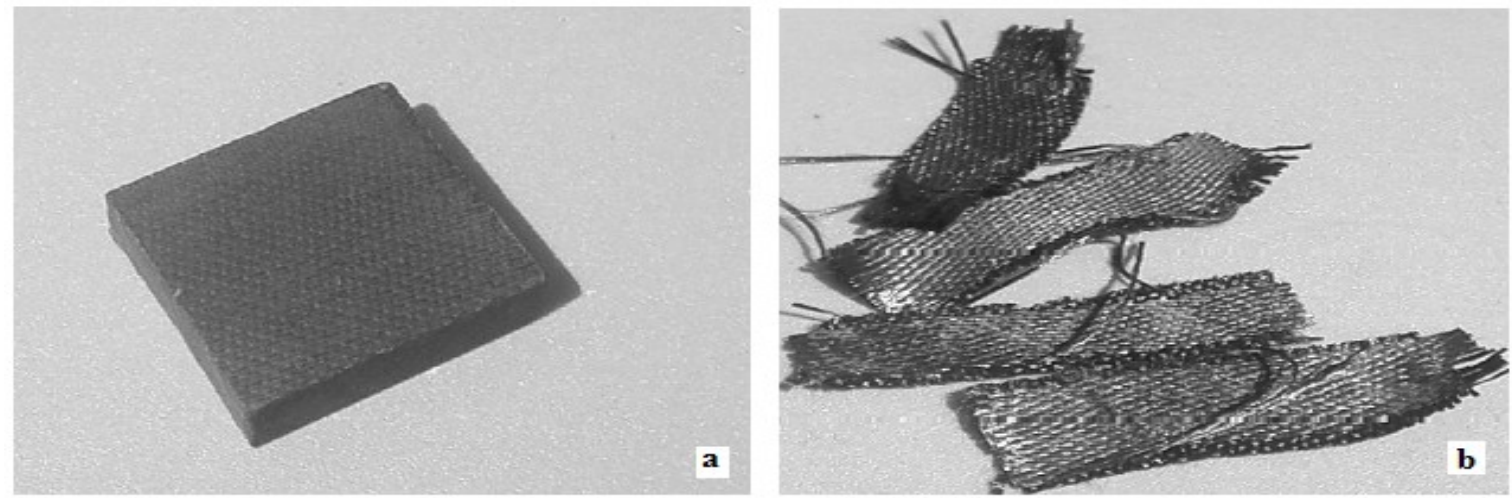

Figure 2: (a) Carbon/phenolic sample composite materials (b) Recovered fibers 


\section{III.1. Characterization of recovered carbon fibers}

Virgin and recovered carbon fibers were analyzed by SEM in order to check their surface quality (Fig.3). Indeed, the SEM micrographs of the recovered fibers (Fig.3b) show that they kept their form. The appearance of the recovered fibers surface in Fig. $3 \mathrm{~b}$ is probably due to some matrix residues adhering, which seems coherent with their diameter slightly larger than that of the virgin fibers (Table 2: 6.98 vs. $6.80 \mu \mathrm{m}$ ). Furthermore, the Fig.3b suggests that the recovered fibers might not be perfectly loose, a feature that would be coherent with the presence of some residual matrix adherent to the fibers.
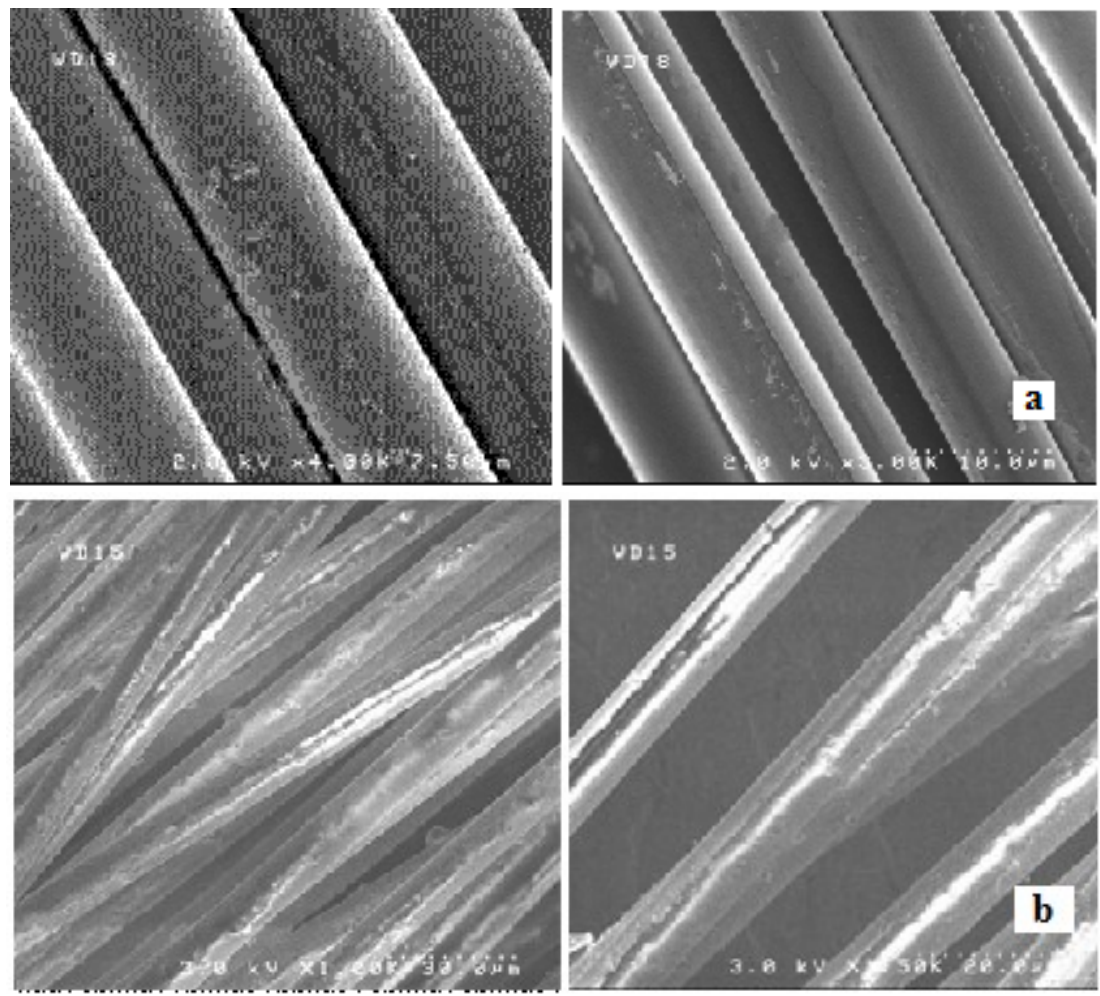

Figure 3: SEM micrographs of surfaces: (a) Virgin fibers (b) Recovered fibers

The mechanical properties of the virgin and recovered fibers were also measured. The results are given in Table 2. The median values of the diameter, the tensile failure stresses, and the Young moduli are close for both samples, suggesting that the fibers were not much altered during the reaction. The strength of the recovered fibers seems slightly lower than that of the virgin fibers (3494 vs. $3688 \mathrm{MPa}$ ). This difference might be within the uncertainty of the measurements. Another explanation could be found in the fact that the diameter of the recovered fibers is slightly higher (matrix residue on fiber surface) yielding a lower failure stress $(\mathrm{F} / \mathrm{S})$.

Table 2: Mechanical characteristics of the carbon fibers

\begin{tabular}{lll}
\hline & Virgin fibers & Recovered fibers \\
\hline Diameter $\mathbf{f}_{\mathbf{v}}(\boldsymbol{\mu m})$ & 6.80 & 6.98 \\
Tensile strength $\square$ (MPa) & 3683 & 3463 \\
Young modulus E (GPa) & 225 & 212 \\
$\mathbf{m}$ & 3.46 & 4.55 \\
$\mathbf{b}$ & -28.807 & -37.49 \\
$\mathbf{l n} \square \mathbf{0 . 5}$ & 8.221 & 8.915 \\
$\square{ }_{\mathbf{0 . 5}}(\mathbf{M P a})$ & 3688 & 3494 \\
\hline
\end{tabular}

To take into account the statistical aspect of the rupture of the fibers, we plotted the Weibull diagram (Fig.4) for each sample, in order to determine the median of the distribution of the stress $(\sigma 0.5)$ and the Weibull modulus (m). The values of $\sigma 0.5$ for the two samples (Table 2) do not vary significantly, which confirms that the treatment of the composite by phenol did not degrade the fibers. Similar results were reported by PiñeroHernanz et al. [19] during the chemical recycling of carbon fibers-reinforced composites in near-critical and supercritical water. 

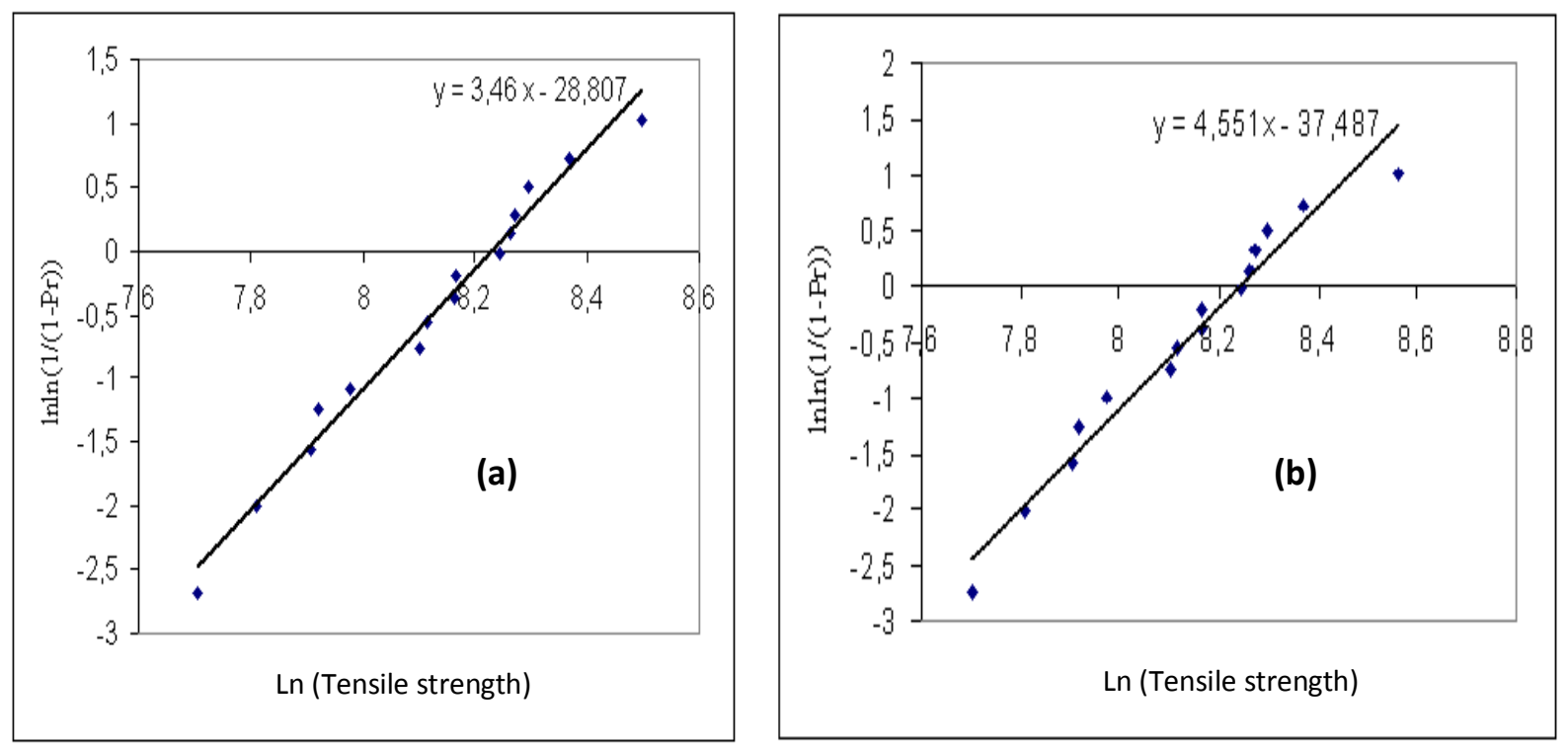

Figure 4: Weibull diagram of carbon fibers: (a) Virgin fibers; (b) Recovered fibers

\section{III.2. Characterization of recovered liquid residue after removal of phenol}

$4 \mathrm{~g}$ of liquid residue coming out of the autoclave yielded $0.73 \mathrm{~g}$ of degraded resin without phenol, from which an amount of $2 \mathrm{~g}$ of recovered product, i.e. almost $60 \%$ of the starting compound, can be extrapolated. Therefore, we performed rapid analyses to check whether this material could be of some interest.

The IR spectrum of the recovered liquid residue (after removal of phenol) is shown in Fig.5 and can be compared to that of the virgin phenolic resin (Fig.6). First, in Fig.5 bands characteristic of phenol (3045, 1500, 1473,886 and $630 \mathrm{~cm}^{-1}$ ) are not observed. Both spectra present bands at $3450 \mathrm{~cm}^{-1}$ (O-H stretching), 3014 $\mathrm{cm}^{-1}$ (aromatic C-H stretching), and in the region $2800-2960 \mathrm{~cm}^{-1}$ (C-H stretching, very intense). Bands at $1530-1600 \mathrm{~cm}^{-1}$ are assigned to aromatic $\mathrm{C}=\mathrm{C}$, those in the region $1000-1250 \mathrm{~cm}^{-1}$ could correspond to $\mathrm{C}-\mathrm{O}$ vibrations, whereas very intense bands in the region $750-860 \mathrm{~cm}^{-1}$ are due to aromatic $\mathrm{C}-\mathrm{H}$ deformations. An increase in the intensity of aromatic carbons bands in the spectrum of the recovered residue was also noticed. This suggests that some phenol was inserted in the structure of the phenolic resin. In their work on chemical recycling of carbon fiber-reinforced epoxy resin in subcritical water by combination of phenol and potassium hydroxide, Liu et al. [12] proposed a possible free-radical mechanism for the decomposition of epoxy resin. They also suggested that phenol might incorporate into the network of epoxy resin. However, they operated under different reaction conditions, in particular a higher phenol/composite ratio.

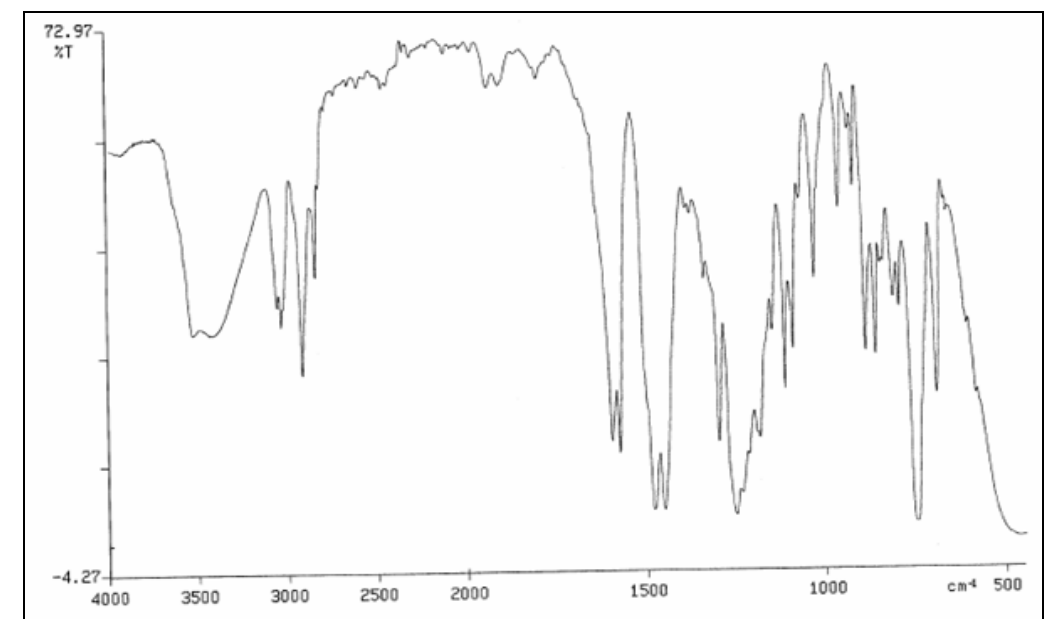

Figure 5: IR spectrum of the recovered residue (after removal of phenol) 


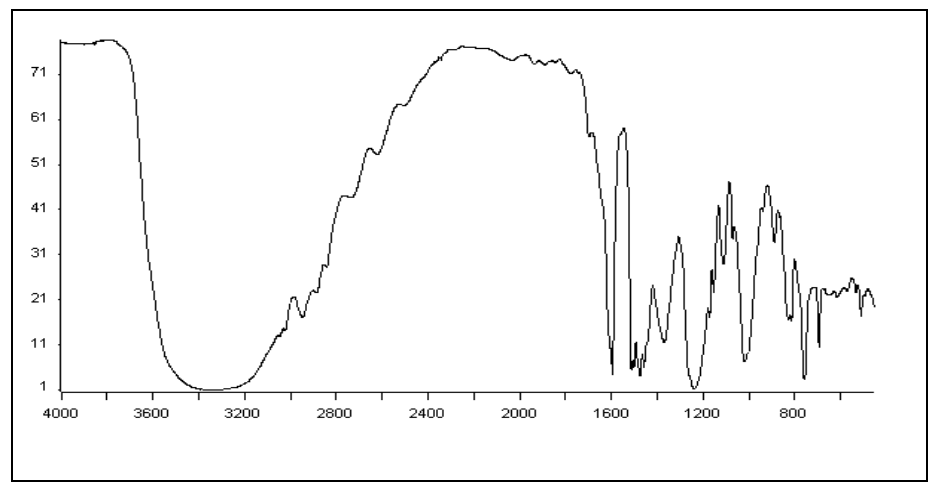

Figure 6: IR spectrum of the virgin phenolic resin

${ }^{1} \mathrm{H}$ (Fig.7 and 8) and ${ }^{13} \mathrm{C}$ (Fig.9 and 10) NMR spectra of the recovered liquid residue and the virgin phenolic resin were also compared. The NMR spectra of the liquid residue are different from those of the virgin resin. The spectra of the virgin resin (Figures 8 and 10) contain peaks not observed in the spectra of the recovered resin (Figures 7 and 9). These peaks can be attributed to carbonyl $\left({ }^{1} \mathrm{H}\right.$ NMR: 2 ppm; ${ }^{13} \mathrm{C}$ NMR: $\sim 200$ ppm) and phenol ( ${ }^{1} \mathrm{H}$ NMR: $5 \mathrm{ppm} ;{ }^{13} \mathrm{C}$ NMR: $150-160 \mathrm{ppm}$ ) functions present in the virgin (uncured) resin. Furthermore, the NMR spectra confirm the attributions of the IR bands. Qualitatively, the ${ }^{13} \mathrm{C}$ NMR spectrum of the degraded resin contains more aromatic carbons (Figure 9, located between 110 and $140 \mathrm{ppm}$ ), compared with that of the virgin resin, which agrees with a possible insertion of phenol into the structure of the phenolic resin.

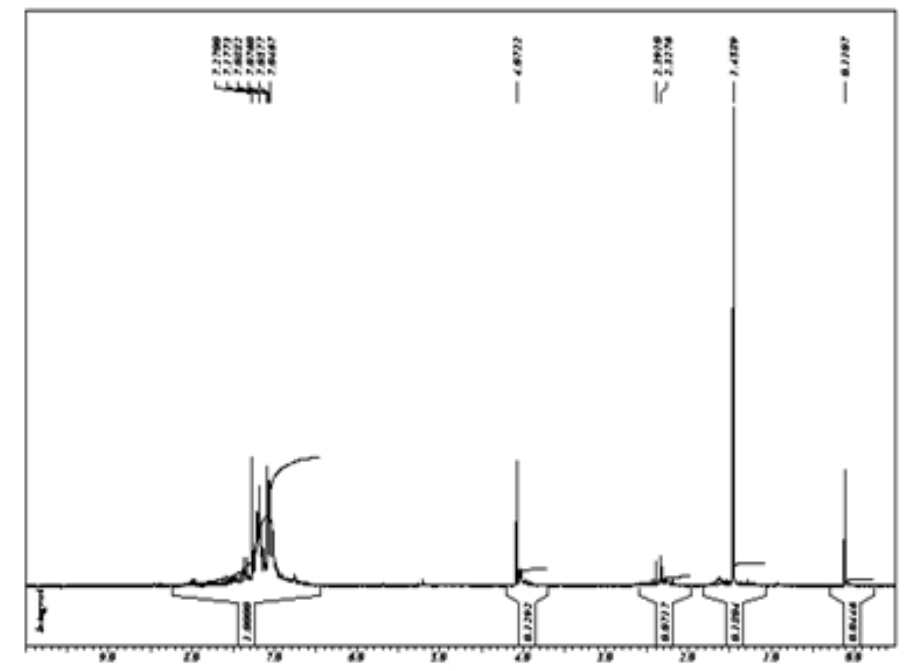

Figure 7: ${ }^{1} \mathrm{H}$ NMR spectrum de of the recovered residue (after removal of phenol)

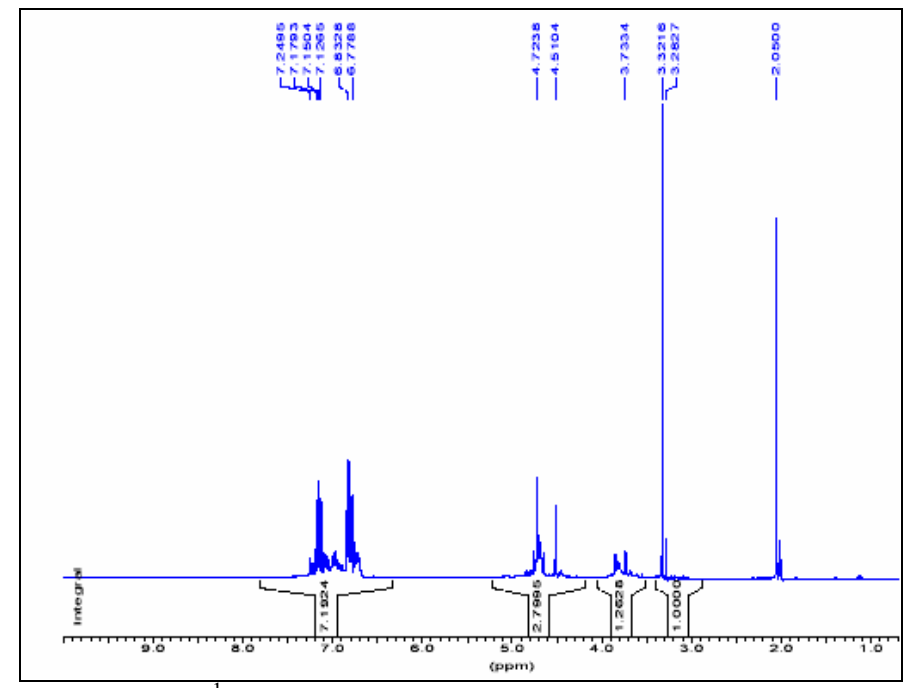

Figure 8: ${ }^{1} \mathrm{H}$ NMR spectrum of the virgin phenolic resin 


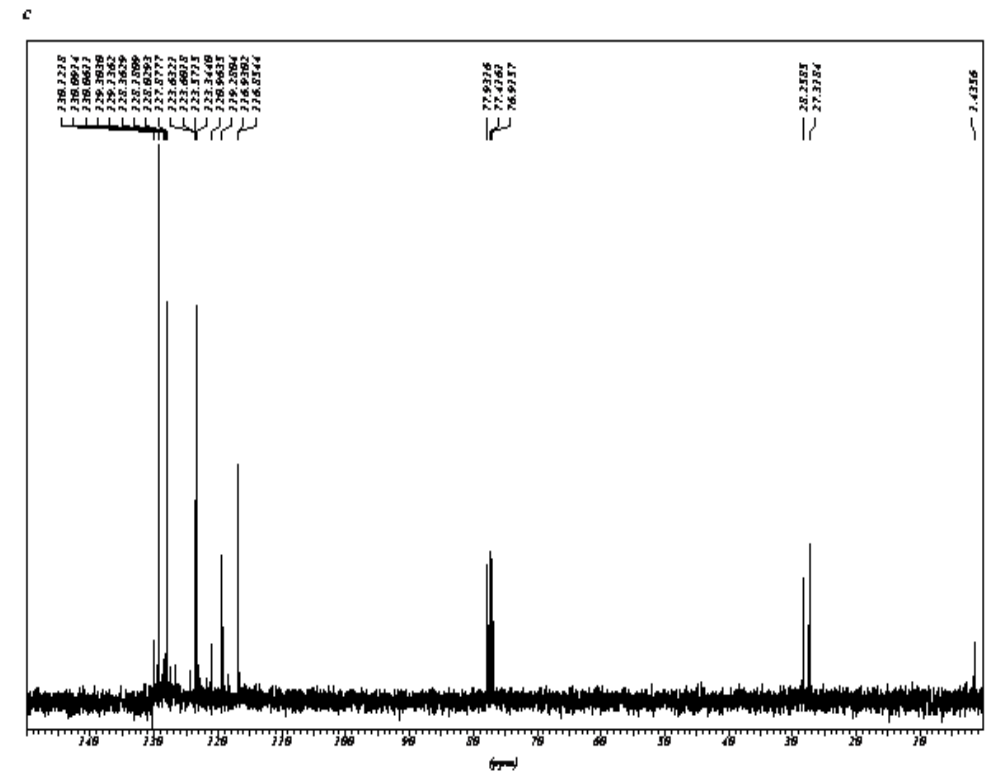

Figure 9: ${ }^{13} \mathrm{C}$ NMR spectrum of the recovered residue (after removal of phenol)

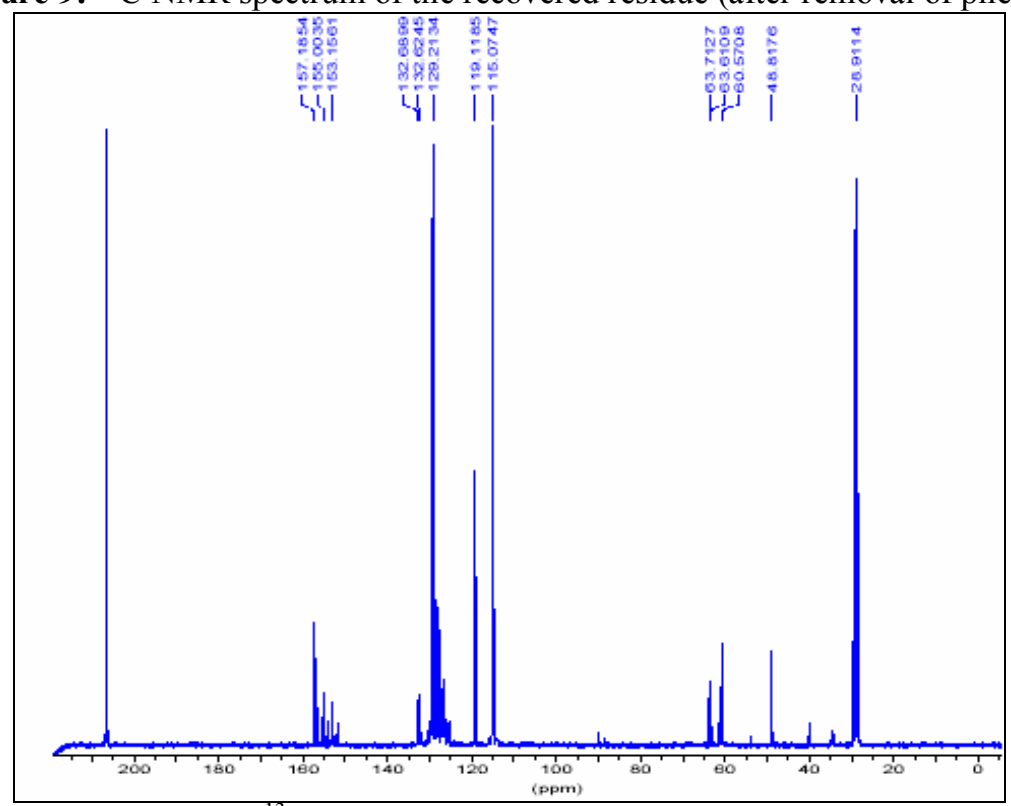

Figure 10: ${ }^{13} \mathrm{C}$ NMR spectrum of the virgin phenolic resin

\section{Conclusion}

In this work, carbon fibers-reinforced phenolic resin composites were subjected to degradation by phenol under relatively mild conditions. The results obtained showed that a temperature of $390{ }^{\circ} \mathrm{C}$ for $4 \mathrm{~h}$ was satisfactory to extract almost completely the organic matrix from the composite, while $95 \%$ of the fibers are recovered. Analysis of the surface with scanning electron microscopy and mechanical characterization of the recovered fibers confirmed that phenol was able to solubilize the matrix of composite materials without altering the carbon fibers. In addition, a rapid examination of the liquid residue showed that the degraded matrix was also potentially recoverable.

\section{References}

[1]. Guide déchets "Valorisation des déchets composites à matrice thermodurcissable" par Agence Rhône-Alpes pour la Maîtrise des Matériaux Projet Recycomp2, (Juin 2005).

[2]. G. Schinner, J. Brandt, and H. Richter, Recycling carbon-fibre-reinforced thermoplastic composites, J Thermoplastic Compos Mater, 9, 1996, 239-245.

[3]. E. Lester, S. Kingman, KH. Wong, C. Rudd, S. Pickering, and N. Hilal, Microwave heating as a means for carbon fibre recovery from polymer, MRS Bull, 39, 2004, 1549-1556.

[4]. SJ. Pickering, Recycling technologies for thermoset composite materials-current status, Compos Part A, 37, $2006,1206-1215$.

[5]. M. Buggy, L. Farragher, and W. Madden, Recycling of composite materials, J Mater Process Technol, 55, 1995, 448-456. 
[6]. SJ. Pickering, H. Yip, JR. Kennerley, and CD. Rudd, The recycling of carbon fibre composites using a fluidised bed process, Proc. $8^{\text {th }}$ International Conference on Fibre Reinforced Composites, 2000, 565-572.

[7]. W. Dang, M. Kubouch, H. Sembokuya, and K. Tsuda, Chemical recycling of glass fiber reinforced epoxy resin cured with amine using nitric acid, Polymer, 46, 2005, 1905-1912.

[8]. R. Piñero-Hernanz, J. García-Serna, C. Dodds, J. Hyde, M. Poliakoff, MJ. Cocero, S. Kingman, S. Pickering, and E. Lester, Chemical recycling of carbon fibre composites using alcohols under subcritical and supercritical conditions, J Supercrit Fluids, 46, $2008,83-92$

[9]. SJ. Pickering, RM. Kelly, JR. Kennerley, NJ. Fenwick, and CD. Rudd, A fluidised-bed process for the recovery of glass fibres from scrap thermoset composites, Compos Sci Technol, 60, 2000, 509-523

[10]. MA. Nahil, and PT. Williams, Recycling of carbon fibre reinforced polymeric waste for the production of activated carbon fibres, J Anal Appl Pyrolysis, 91, 2011, 67-75.

[11]. Y. Bai, Z. Wang, and L. Feng, Chemical recycling of carbon fibers reinforced epoxy resin composites in oxygen in supercritical water, Mater Design, 31, 2010, 999-1002.

[12]. Y. Liu, Y. Liu, Z. Jiang, and T. Tang, Chemical recycling of carbon fiber reinforced epoxy resin composites in subcritical water: Synergistic effect of phenol and KOH on the decomposition efficiency, Polym Degrad Stab, 97, 2012, 214-220.

[13]. P. Gagnaire, P. Delhaes, and A.Pacault, Analyse des images optiques observées par diffraction d'un faisceau laser sur des fibres de carbone, J Chem Phys, 84, 1987, 1407-1413.

[14]. A. Anderko, Association and semiempirical equations of state, J Chem Soc, 86,Faraday Trans 1990, 2823-2830.

[15]. D.Ambrose, Critical temperatures of same phenols and other organic compounds, J Chem Soc, 59, Faraday Trans 1963, 1988-1993.

[16]. BE.Leach, Disproportionation of highly alkylated phenols with phenol, Continental Oil Co,USA, Brevet. 77-852389[4125736] (1977).

[17]. A . Abourriche, M. Oumam, H. Hannache, R. Pailler, R. Naslain, M. Birot, and JP. Pillot, Récupération à l'autoclave de la matière organique de schistes bitumineux Marocains par le phénol en conditions subcritiques, Ann chimie - Science des matériaux, 30, 2005, 1-17.

[18]. A. Abourriche, M. Oumam, H. Hannache, R. Pailler, R. Naslain, M. Birot, and JP. Pillot, New pitches with enhanced graphitization ability obtained from Moroccan oil shales, J Anal Appl Pyrolysis, 71, 2004, 935-944.

[19]. R. Piñero-Hernanz, C. Dodds, J. Hyde, J. García-Serna, M. Poliakoff, E. Lester, MJ. Cocero, S. Kingman, S. Pickering, and KH. Wong, Chemical recycling of carbon fibre reinforced composites in nearcritical and supercritical water, Compos Part A, 39, 2008, 454-461. 